\title{
Modeling the Migration of 2,6-di-tert-butyl-p-cresol from Plastic Bags into attiéké (Cassava Couscous) from Physico-Chemical and Morphometric Parameters
}

\author{
Mananga Olivier Simon Kombo ${ }^{1}$, Mamadou Guy-Richard Kone ${ }^{2}$, Yapo Habib Kpidi ${ }^{1}$, \\ Agnes Essoh Jean Eudes Yves Gnagne ${ }^{1}$, Tiama Guy Nicaise Ballet ${ }^{1}$, Ossey Bernard Yapo ${ }^{1,3}$ \\ ${ }^{1}$ Environemental Sciences Laboratory, Environmental Science and Management Department, Nangui Abrogoua University, Abidjan, Ivory \\ Coast \\ ${ }^{2}$ Laboratory of Thermodynamics and Environmental Physico-Chemistry, Basic and Applied Sciences Department, Nangui Abrogoua \\ University, Abidjan, Ivory Coast \\ ${ }^{3}$ Environmental Central Laboratory, Ivorian Anti-pollution Centre, Abidjan, Ivory Coast
}

\section{Email address:}

komanols@yahoo.fr (M. O. S. Kombo)

\section{To cite this article:}

Mananga Olivier Simon Kombo, Mamadou Guy-Richard Kone, Yapo Habib Kpidi, Agnes Essoh Jean Eudes Yves Gnagne, Tiama Guy Nicaise Ballet, Ossey Bernard Yapo. Modeling the Migration of 2,6-di-tert-butyl-p-cresol from Plastic Bags into attiéké (Cassava Couscous) from Physico-Chemical and Morphometric Parameters. American Journal of Environmental Protection. Vol. 9, No. 1, 2020, pp. 1-9. doi: 10.11648/j.ajep.20200901.11

Received: November 28, 2019; Accepted: January 13, 2020; Published: February 4, 2020

\begin{abstract}
Attiéké, couscous made from fermented cassava, is a staple food in Côte d'Ivoire packaged in polythene plastic bags. The antioxidant BHT was analyzed both in the plastic bags and in the attiéké at different temperatures and at different levels inside the attiéké ball. A modelling study was conducted to determine a quantitative relationship between the BHT concentration in the attiéké and the descriptors which are the concentration of BHT in the plastic bag, grain size, depth (from the surface to inside the attiéké ball), duration and conditioning temperature of the attiéké in the plastic bags. BHT, initially not detected in the attiéké, migrates there depending on the packaging temperature of this commodity and certain parameters. This study was conducted by using multiple linear regression. A quantitative model was proposed. The statistical indicators revealed effective predictions with the determination coefficient equal to 0.92 and the standard error equal to 0.191 . The value of the Fischer test was 170.250 and the cross-validation determination coefficient was 0.9136 . The results obtained suggest that the combination of the descriptors used could be useful in predicting attiéké contamination by plastic bags. Temperature is the most important descriptor for predicting the BHT concentration in the attiéké with a normalized coefficient equal to 0.846 followed by depth (from the surface to inside the attiéké ball) (-0.822).
\end{abstract}

Keywords: Modelling, Migration, attiéké, BHT, Plastic Bags, Physico-Chemical Descriptors

\section{Introduction}

BHT (2,6-di-tert-butyl-p-cresol) is a substance used as an antioxidant in plastic bags. It belongs to the group of hindered phenol antioxidants. Antioxidants are used to prevent discoloration, lack of flexibility and strength of the plastic polymer [1]. This compound is one of the endocrine disrupters [2]. Varuna et al. have demonstrated that BHT has a hepatotoxic effect [3]. Unfortunately, this substance can contaminate the attiéké during its packaging in plastic bags. Attiéké is a couscous produced from the fermentation of cassava. It is a staple food in Côte d'Ivoire. Its annual production is estimated between 18,965 tons and 40,000 tons [4]. According to European Union Regulation EC No. $10 / 2011$, the specific migration limit (SML) for BHT is 3 $\mathrm{mg} / \mathrm{Kg}$ [5]. The quantification of plastic bag additives in the attiéké is a long and costly process in terms of the equipment used and the chemicals. To overcome its difficulties, alternative methods for predicting food contamination with BHT are proposed. Modeling is one of the approaches used to study the migration of contaminants in food or food simulants. Based on the Quantity-Structure-Property 
Relationship (QSPR) or Quantity-Structure-Activity Relationship (QSAR), a predictive model based on physicochemical descriptors was determined [6, 7]. This statistical approach allows the use of methods such as linear regression, non-linear regression.

A statistical model is a simplified and quantified representation of a phenomenon. It leads us to a better understanding of reality and even make predictions. It allows, through mathematical equations involving parameters, to explain or predict a variable (dependent variable or variable to be explained) by explanatory variables (independent variables) [8]. Traistaru et al. developed a statistical prediction model to determine global migration (dependent variable) from temperature and time (independent variables) in food simulants [9]. Musoke et al. studied the migration of chemical contaminants from polyethylene bags into food during cooking [10]. For the time being, no reference is found about the migration of pollutant in attiéké. So, it is interesting to develop a mathematical model to predict the migration of pollutant in a solid food like attiéké.

The general objective of this work is to determine a statistical model using multilinear regression capable of predicting the transfer of the additive (BHT) into the attiéké packaged in plastic bags from morphometric (grain size and different levels within the attiéké ball) and environmental variables related to its packaging. In particular, it is necessary to identify explanatory and relevant variables favourable to the transfer of the pollutant in order to generate the mechanisms for better quality packaging of attiéké for good consumer health.

\section{Material and Methods}

\subsection{Material}

The study material consists of attiéké packaged in plastic bags sold in shops. The modeling was carried out using the multilinear regression method implemented in the Excel tables $[11,12]$.

\subsection{Sampling}

Three-stage cluster sampling method was used. At the primary level, the three cities of southern Côte d'Ivoire, Dabou, Jacqueville and Abidjan, known as the main attiéké producing cities [4]. At the secondary level, four municipalities in the city of Abidjan (Abobo, Attécoubé, Cocody, Marcory), 1 village in the city of Dabou and 1 village in the city of Jacqueville. Attiéké production sites constitute the tertiary level [4]. The normal attiéké "small grain" was collected from production sites in Dabou, Jacqueville and Aboboté in the municipality of Abobo. As for the "big grain" attiéké called «agbodjama», it was collected from production sites in Anono in the commune of Cocody, Anoumambo in the commune of Marcory and Abobodoumé in the commune of Attécoubé. At each site, approximately $200 \mathrm{~g}$ of attiéké were collected. Samples were taken at $70^{\circ} \mathrm{C}, 60^{\circ} \mathrm{C}, 50^{\circ} \mathrm{C}, 40^{\circ} \mathrm{C}$ and $30^{\circ} \mathrm{C}$. For each temperature, 9 samples were taken and packaged in plastic bags from 3 different plants. After each conditioning period (1 hour, 2 hours and 3 hours), using stainless steel pliers, $5 \mathrm{~g}$ of attiéké were collected at different depth levels of the attiéké ball: at the surface (up to $0.5 \mathrm{~cm}$ ), at $1 \mathrm{~cm}$ and at 1.5 $\mathrm{cm}$. A total of 45 attiéké balls were collected from each site and 270 attiéké balls were collected from all 6 sites. The control consists of the attiéké taken under the same conditions and introduced into a brown glass vial [13].

\subsection{Antioxidant BHT Analyses}

The analyses were performed by high performance liquid chromatography using the method described by Kombo et al. [14].

\subsection{Physico-chemical Descriptors}

The concentration of additives migrating from plastic bags in the attiéké might depend on several parameters. According to Musoke et al., the migration of chemical contaminants from polyethylene bags to food depends on temperature, duration and depth level (from the surface to the interior of the food) [10]. It is essential to calculate or measure a large number of different descriptors in order to determine which ones are the most relevant to the established model. Each model is based on a number of descriptors used by the latter. According to Topliss and Edwards and according to Ghamadi et al., the maximum number of descriptors used should be about one-fifth of the number of learning game observations included in the model $[15,16]$. A method for selecting the explanatory variables, including step-by-step method, was carried out. The latter consists in incorporating the variables into the model one by one by selecting at each step, the variable whose partial correlation with the modelled quantity allow to increase the determination coefficient $\left(R^{2}\right)$. At each step, the significance of the partial correlations of the previously introduced variables is verified [16]. Thus, several descriptors that may influence the migration of pollutants are used to predict the concentration of contaminants in the attiéké.

The descriptors considered in this study are: the concentration of BHT in the plastic bag, the size of the grains, the depth level (from the surface to inside the attiéké ball), the duration and temperature of conditioning of the attiéké in the plastic bags. Temperature is one of the most important kinetic factors in the mechanisms for transferring pollutants from one matrix to another. It plays a fundamental role in the kinetics of physico-chemical and biological reactions as well as the value of equilibrium constants [17].

\subsection{Estimation of the Predictive Capacity of a Model}

The concentration of BHT in attiéké was presented by 120 study samples with a concentration range from 1.01 to $3.46 \mathrm{mg} / \mathrm{kg}$. This range of concentrations with reduced variation makes it possible to define a better quantitative 
relationship between the concentration of BHT in the attiéké and the physico-chemical descriptors of the samples taken. The quality of the model is determined by taking into account various statistical indicators such as the determination coefficient $\left(\mathrm{R}^{2}\right)$, standard error (RMSE), Fischer test (F) and cross-validation determination coefficient $\left(Q_{C V}^{2}\right)$. These indicators provide information on the adjustment of theoretical and experimental values. They allow the quality of the model to be assessed and its accuracy to be expressed [18]. The determination coefficient $\mathrm{R}^{2}$ gives an evaluation of the dispersion of the calculated values around the experimental values. The quality of the model is better when the points evaluated by $\mathrm{R}^{2}$ are close to the adjustment line. The determination coefficient $\left(\mathrm{R}^{2}\right)$ is given by the expression:

$$
R^{2}=1-\frac{\sum\left(y_{i, \exp }-\hat{y}_{i, t h e ́ o}\right)^{2}}{\sum\left(y_{i, \exp }-\bar{y}_{i, \exp }\right)^{2}}
$$

The standard error or standard deviation (RMSE) is used to assess the reliability and accuracy of the model. Its expression is as follows:

$$
R M S E=\sqrt{\frac{\sum\left(y_{i, e x p}-y_{i, t h e ́ o}\right)^{2}}{n-k-1}}
$$

Concerning the Fischer F test, it is useful for the choice of the model's constituent descriptors. The Fischer test is given by the mathematical equation:

$$
\mathrm{F}=\frac{\sum\left(y_{i, t h e ́ o}-y_{i, \text { exp }}\right)^{2}}{\sum\left(y_{i, \text { exp }}-y_{i, t h e ́ o}\right)^{2}} * \frac{n-k-1}{k}
$$

The coefficient for determining the cross-validation is obtained by the equation :

$$
Q_{C V}^{2}=\frac{\sum\left(y_{i, t h e ́ o}-\bar{y}_{i, \text { exp }}\right)^{2}-\sum\left(y_{i, t h e ́ o}-y_{i, \text { exp }}\right)^{2}}{\sum\left(y_{i, t h e ́ o}-\bar{y}_{i, \text { exp }}\right)^{2}}
$$

In these equations, $\mathrm{k}$ is the number of descriptors, $\mathrm{n}$ is the number of observations of the test set and n-k-1 is the degree of freedom [19].

$y_{i, \text { exp }}$ is the experimental value of the BHT concentration of the attiéke, $\hat{y}_{i, t h e ́ o}$ is the theoretical value of the BHT concentration in the attiéké and $\bar{y}_{i, \text { exp }}$ the experimental mean value of the BHT concentration in the attiéké.

\subsection{Statistical Analyses}

\subsubsection{Principal Component Analysis (PCA)}

Principal Component Analysis is a data analysis tool that aims to explain the structure of correlations or covariances. It uses linear combinations of the original data and allows the data to be interpreted (Soro et al., 2018). In this study, the PCA was used not only to assess the relationships between the different variables measured, but also to correlate the physico-chemical descriptors obtained with the concentrations of BHT migrating from plastic bags to attiéké.

\subsubsection{Multiple Linear Regression (MLR)}

Multiple linear regression is a statistical method that can be used to determine a relationship between the dependent variable and several independent variables (descriptors). This statistical method minimizes the differences between actual and predicted values. It also makes it possible to identify the most influential descriptors. It is the most widely used tool for studying multidimensional data. It is based on the $y$ function of the XLSTAT statistical software whose equation is of the form:

$\mathrm{Y}=\mathrm{a}+\left(\mathrm{bx}_{1}+\mathrm{cx}_{2}+\mathrm{dx}_{3}+\mathrm{ex}_{4}\right)+\left(\mathrm{fx}_{12}+\mathrm{gx}_{22}+\mathrm{gx}_{32}+\mathrm{hx}_{42}\right)$ where $a, b, c .$. represent the parameters and $x_{1}, x_{2}, x_{3} \ldots$ variables.

The quality of the model developed depends on its validation. Indeed, in order to estimate its predictive power, additional experimental data are essential [16]. The MLR was determined using the XLSTAT statistical software version 2014.

\subsubsection{Reporting of Predicted and Experimental Data}

From the validation set, the model is acceptable when the relationships between theoretical and experimental values are close to unity [6].

\subsection{Criteria for Accepting a Model}

The more strongly the experimental values are correlated with the theoretical values, the closer the determination coefficient $\left(\mathrm{R}^{2}\right)$ is to one (1).

$\mid R^{2}-R^{2}$ adj $\mid \leq 0.3$, translates that the number of descriptors involved in the model is acceptable. A predictive model is acceptable when the RMSE is less than 0.3. However, the excellent values of $\mathrm{R}^{2}$ and RMSE are not sufficient to validate a good model. Additional indicators such as the cross-validation determination coefficient $Q_{C V}^{2}$ are required to determine the predictive capability of a model.

A predictive model is considered good when $\left|\mathrm{R}^{2}-Q_{C V}^{2}\right|$ $<0.3[21]$.

A model is considered good if $Q_{C V}^{2}>0.5$ and excellent if $Q_{C V}^{2}>0.9[22]$.

\section{Results}

\subsection{BHT Analysis Results}

Eighty (80) samples used to calibrate the model (learning or test set) and the other 40 samples used to validate it (validation set) are recorded in Table 1 . In this study, there are 5 descriptors. Table 1 presents the concentrations of BHT in attiéké $\left(\mathrm{C}_{\mathrm{BHT}}\right.$ Attiéké $)$ according to different descriptors. The concentration of BHT in attiéké varies from 1.01 to 3.46 $\mathrm{mg} / \mathrm{kg}$. $\mathrm{C}_{\text {BHTSachet }}$ is the concentration of BHT in plastic bags in $\mathrm{mg} / \mathrm{Kg}$, Tgrain is the size of the attiéké grains in $\mathrm{mm}, \mathrm{T}$ is the packaging temperature of the attiéké in degrees Celsius $\left({ }^{\circ} \mathrm{C}\right), \mathrm{D}$ is the packaging duration in hours and $\mathrm{P}$ is the depth level of the attiéké ball in cm (from surface to inside attiéké ball). 
Table 1. BHT concentrations according to the different descriptors.

\begin{tabular}{|c|c|c|c|c|c|c|c|c|c|c|c|c|c|}
\hline Observation & $\mathrm{C}_{\text {BHTsachet }}$ & $T_{\text {grain }}$ & $\mathbf{T}$ & D & $\mathbf{P}$ & $\mathrm{C}_{\text {BHTattiéké }}$ & Observation & $\mathrm{C}_{\text {BHTsachet }}$ & $\mathbf{T}_{\text {grain }}$ & $\mathbf{T}$ & D & $\mathbf{P}$ & $\mathrm{C}_{\text {BHTattiéké }}$ \\
\hline \multicolumn{14}{|l|}{ Training set } \\
\hline 1 & 26 & 1,1 & 70 & 1 & 0,5 & 3,13 & 41 & 18 & 1,1 & 70 & 3 & 0,5 & 3,12 \\
\hline 2 & 26 & 1,1 & 70 & 1 & 1 & 2,32 & 42 & 18 & 1,1 & 50 & 2 & 0,5 & 1,69 \\
\hline 3 & 26 & 1,1 & 70 & 2 & 0,5 & 3,34 & 43 & 18 & 1,3 & 70 & 1 & 0,5 & 3,01 \\
\hline 4 & 26 & 1,1 & 70 & 2 & 1 & 2,56 & 44 & 18 & 1,3 & 70 & 2 & 0,5 & 3,11 \\
\hline 5 & 26 & 1,1 & 60 & 2 & 1 & 1,63 & 45 & 18 & 1,3 & 50 & 2 & 0,5 & 1,91 \\
\hline 6 & 26 & 1,1 & 60 & 3 & 0,5 & 2,93 & 46 & 18 & 1,3 & 50 & 3 & 0,5 & 1,97 \\
\hline 7 & 26 & 1,1 & 60 & 3 & 1 & 1,66 & 47 & 18 & 0,8 & 70 & 1 & 0,5 & 3,04 \\
\hline 8 & 26 & 1,1 & 40 & 1 & 0,5 & 1,53 & 48 & 18 & 0,8 & 70 & 3 & 1 & 2,32 \\
\hline 9 & 26 & 1,1 & 40 & 2 & 0,5 & 1,93 & 49 & 18 & 0,8 & 60 & 1 & 0,5 & 2,57 \\
\hline 10 & 26 & 1,3 & 70 & 2 & 1 & 2,13 & 50 & 18 & 0,8 & 60 & 3 & 1 & 1,48 \\
\hline 11 & 26 & 1,3 & 70 & 3 & 0,5 & 3,41 & 51 & 18 & 2,4 & 70 & 2 & 0,5 & 3,19 \\
\hline 12 & 26 & 1,3 & 70 & 3 & 1 & 2,16 & 52 & 18 & 2,4 & 70 & 2 & 1 & 2,06 \\
\hline 13 & 26 & 1,3 & 60 & 1 & 1 & 1,5 & 53 & 18 & 2,4 & 70 & 3 & 1 & 2,15 \\
\hline 14 & 26 & 1,3 & 60 & 3 & 0,5 & 2,88 & 54 & 18 & 2,4 & 60 & 1 & 0,5 & 2,23 \\
\hline 15 & 26 & 1,3 & 60 & 3 & 1 & 1,66 & 55 & 18 & 2,4 & 60 & 2 & 0,5 & 2,28 \\
\hline 16 & 26 & 1,3 & 50 & 3 & 1 & 1,09 & 56 & 18 & 2,4 & 50 & 3 & 0,5 & 2,16 \\
\hline 17 & 26 & 1,3 & 40 & 1 & 0,5 & 1,42 & 57 & 18 & 2,8 & 70 & 1 & 0,5 & 2,89 \\
\hline 18 & 26 & 0,8 & 70 & 2 & 1,5 & 1,33 & 58 & 18 & 2,8 & 70 & 2 & 0,5 & 2,96 \\
\hline 19 & 26 & 0,8 & 70 & 3 & 0,5 & 3,46 & 59 & 18 & 2,8 & 50 & 3 & 0,5 & 2,28 \\
\hline 20 & 26 & 0,8 & 70 & 3 & 1,5 & 1,6 & 60 & 18 & 2,1 & 70 & 1 & 0,5 & 3,01 \\
\hline 21 & 26 & 0,8 & 60 & 1 & 1 & 1,64 & 61 & 18 & 2,1 & 70 & 1 & 1 & 1,79 \\
\hline 22 & 26 & 0,8 & 60 & 2 & 0,5 & 3,07 & 62 & 18 & 2,1 & 70 & 2 & 0,5 & 3,1 \\
\hline 23 & 26 & 0,8 & 60 & 2 & 1 & 1,99 & 63 & 18 & 2,1 & 60 & 2 & 0,5 & 2,42 \\
\hline 24 & 26 & 0,8 & 60 & 3 & 0,5 & 3,15 & 64 & 18 & 2,1 & 50 & 2 & 0,5 & 2,13 \\
\hline 25 & 26 & 0,8 & 50 & 2 & 1 & 1,02 & 65 & 24 & 1,1 & 70 & 1 & 0,5 & 3,12 \\
\hline 26 & 26 & 2,4 & 70 & 1 & 1 & 2,2 & 66 & 24 & 1,1 & 70 & 3 & 1 & 2,83 \\
\hline 27 & 26 & 2,4 & 70 & 2 & 0,5 & 2,81 & 67 & 24 & 1,1 & 60 & 1 & 0,5 & 2,19 \\
\hline 28 & 26 & 2,4 & 60 & 3 & 0,5 & 2,41 & 68 & 24 & 1,1 & 60 & 2 & 0,5 & 2,23 \\
\hline 29 & 26 & 2,4 & 50 & 1 & 0,5 & 1,96 & 69 & 24 & 1,1 & 50 & 1 & 0,5 & 1,87 \\
\hline 30 & 26 & 2,4 & 50 & 3 & 0,5 & 2,06 & 70 & 24 & 1,3 & 70 & 2 & 0,5 & 3,32 \\
\hline 31 & 26 & 2,4 & 40 & 3 & 0,5 & 1,15 & 71 & 24 & 1,3 & 70 & 2 & 1 & 2,19 \\
\hline 32 & 26 & 2,8 & 70 & 1 & 0,5 & 3,09 & 72 & 24 & 1,3 & 70 & 3 & 1 & 2,23 \\
\hline 33 & 26 & 2,8 & 70 & 1 & 1 & 2,06 & 73 & 24 & 1,3 & 60 & 1 & 0,5 & 2,76 \\
\hline 34 & 26 & 2,8 & 70 & 2 & 1 & 2,16 & 74 & 24 & 1,3 & 50 & 2 & 0,5 & 2,41 \\
\hline 35 & 26 & 2,8 & 50 & 1 & 0,5 & 1,87 & 75 & 24 & 0,8 & 70 & 1 & 0,5 & 3,25 \\
\hline 36 & 26 & 2,8 & 40 & 1 & 0,5 & 1,14 & 76 & 24 & 0,8 & 70 & 2 & 0,5 & 3,34 \\
\hline 37 & 26 & 2,1 & 70 & 2 & 0,5 & 3,21 & 77 & 24 & 2,4 & 70 & 1 & 0,5 & 3,04 \\
\hline 38 & 26 & 2,1 & 70 & 3 & 0,5 & 3,26 & 78 & 24 & 2,4 & 50 & 2 & 0,5 & 2,39 \\
\hline 39 & 26 & 2,1 & 60 & 2 & 1 & 1,59 & 79 & 24 & 2,4 & 50 & 3 & 0,5 & 2,43 \\
\hline 40 & 18 & 1,1 & 70 & 1 & 0,5 & 2,92 & 80 & 24 & 2,8 & 70 & 1 & 0,5 & 3,11 \\
\hline \multicolumn{14}{|l|}{ Validation set } \\
\hline 81 & 26 & 1,1 & 50 & 2 & 0,5 & 2,47 & 101 & 26 & 2,1 & 60 & 3 & 1 & 1,62 \\
\hline 82 & 26 & 1,1 & 50 & 3 & 0,5 & 2,73 & 102 & 26 & 2,1 & 60 & 3 & 1,5 & 1,01 \\
\hline 83 & 26 & 1,3 & 60 & 2 & 0,5 & 2,81 & 103 & 26 & 2,1 & 50 & 1 & 0,5 & 2,01 \\
\hline 84 & 26 & 1,3 & 60 & 2 & 1 & 1,61 & 104 & 26 & 2,1 & 50 & 2 & 0,5 & 2,11 \\
\hline 85 & 26 & 1,3 & 50 & 3 & 0,5 & 2,24 & 105 & 26 & 2,1 & 40 & 3 & 0,5 & 1,14 \\
\hline 86 & 26 & 0,8 & 70 & 3 & 1 & 2,92 & 106 & 18 & 1,1 & 70 & 1 & 1 & 1,63 \\
\hline 87 & 26 & 0,8 & 50 & 3 & 0,5 & 2,8 & 107 & 18 & 1,1 & 70 & 2 & 0,5 & 3,02 \\
\hline 88 & 26 & 2,4 & 70 & 1 & 0,5 & 2,73 & 108 & 18 & 1,1 & 70 & 2 & 1 & 1,87 \\
\hline 89 & 26 & 2,4 & 70 & 2 & 1 & 2,31 & 109 & 18 & 1,1 & 50 & 1 & 0,5 & 1,6 \\
\hline 90 & 26 & 2,4 & 70 & 3 & 0,5 & 2,88 & 110 & 18 & 1,1 & 50 & 3 & 0,5 & 1,73 \\
\hline 91 & 26 & 2,4 & 60 & 3 & 1 & 1,58 & 111 & 18 & 0,8 & 60 & 2 & 0,5 & 2,58 \\
\hline 92 & 26 & 2,4 & 50 & 2 & 0,5 & 2,01 & 112 & 18 & 0,8 & 60 & 2 & 1 & 1,27 \\
\hline 93 & 26 & 2,8 & 70 & 2 & 0,5 & 3,14 & 113 & 18 & 2,4 & 70 & 3 & 0,5 & 3,23 \\
\hline 94 & 26 & 2,8 & 60 & 3 & 1 & 1,37 & 114 & 18 & 2,1 & 50 & 3 & 0,5 & 2,16 \\
\hline 95 & 26 & 2,8 & 50 & 2 & 0,5 & 1,91 & 115 & 24 & 1,3 & 70 & 3 & 0,5 & 3,39 \\
\hline 96 & 26 & 2,8 & 50 & 3 & 0,5 & 1,96 & 116 & 24 & 1,3 & 50 & 3 & 0,5 & 2,43 \\
\hline 97 & 26 & 2,1 & 70 & 1 & 1,5 & 1,01 & 117 & 24 & 0,8 & 50 & 2 & 0,5 & 2,61 \\
\hline 98 & 26 & 2,1 & 70 & 2 & 1 & 2,12 & 118 & 24 & 0,8 & 50 & 3 & 0,5 & 2,69 \\
\hline 99 & 26 & 2,1 & 70 & 3 & 1 & 2,15 & 119 & 24 & 2,4 & 60 & 3 & 0,5 & 2,81 \\
\hline 100 & 26 & 2,1 & 60 & 3 & 0,5 & 3,09 & 120 & 24 & 2,8 & 70 & 2 & 0,5 & 3,21 \\
\hline
\end{tabular}




\subsection{Principal Component Analysis (PCA) Result}

The table 2 presents factorial weights of variables PCA. The cumulative variances of the three factors are $68.2 \%$. This percentage is close to $70 \%$ so most of the information is expressed. The factor 1 is strongly and positively correlated to the concentration of BHT in attiéké. Concerning factor 2, it is positively correlated to the packaging temperature (T) and to depth of attiéké ball (P). About factor 3, it is negatively correlated to the packaging duration (D).

Table 2. Variances and Factor weights of PCA variables.

\begin{tabular}{llll}
\hline & Fact. 1 & Fact. 2 & Fact. 3 \\
\hline \% Variance & 28,49 & 22,34 & 17,49 \\
Cumulative variance & 28,489 & 50,83 & 68,32 \\
Variables factor weigh & & & \\
C $_{\text {BHTsachet }}$ & $-0,425$ & 0,025 & $-0,321$ \\
Tgrain & 0,069 & $-0,264$ & 0,388 \\
T & 0,474 & 0,848 & 0,017 \\
D & $-0,226$ & $-0,079$ & $-0,823$ \\
P & $-0,650$ & 0,733 & 0,084 \\
$\mathrm{C}_{\text {BHTattiéké }}$ & 0,909 & 0,094 & $-0,333$ \\
\hline
\end{tabular}

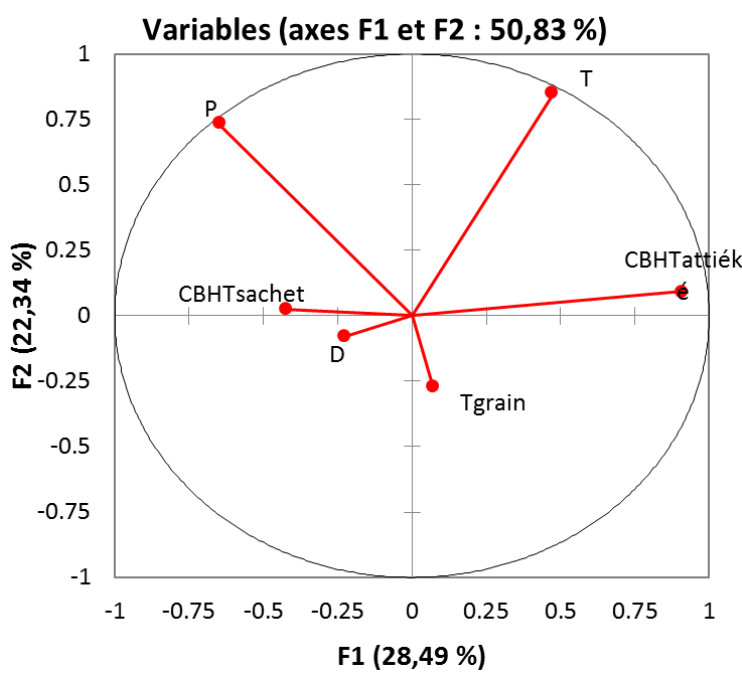

Figure 1. Projection of variables in factorial plane $F_{1} X F_{2}$.

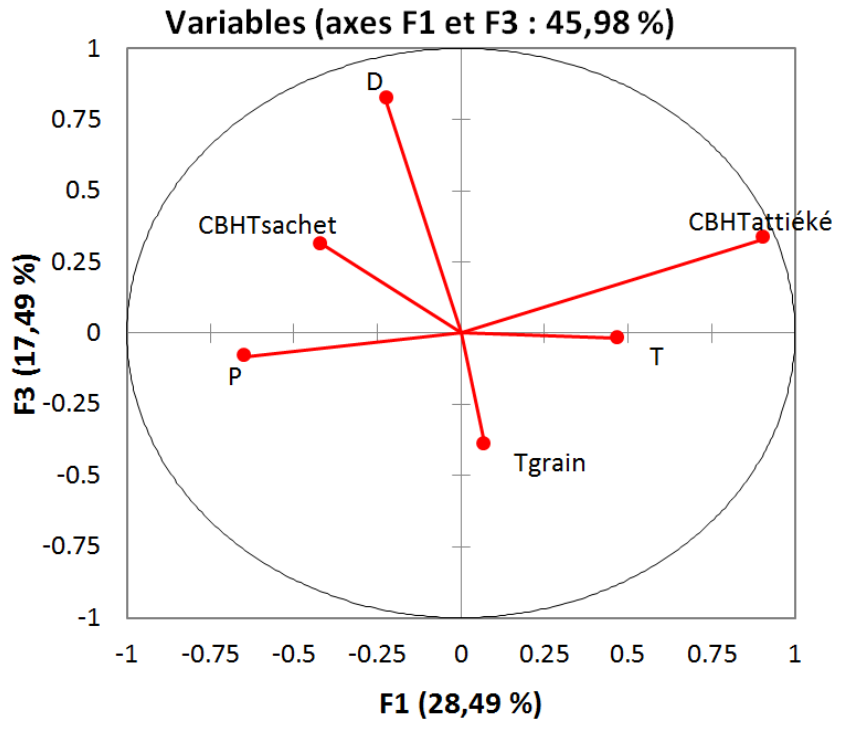

Figure 2. Projection of variables in factorial plane $F_{1} X F_{3}$.

The figure 1 shows variables projection in the factorial plane $\mathrm{F}_{1} \mathrm{X} \mathrm{F}_{2}$. This plan shows that the concentration of BHT in attiéké $\left(\mathrm{C}_{\mathrm{BHTattiéké}}\right)$ is inversely proportional to the depth level of the attiéké ball. As for the $\mathrm{F}_{2}$ factor, its analysis shows that the temperature and depth level of attiéké ball change proportionally. The factorial plane $\mathrm{F}_{1} \mathrm{X} \mathrm{F}_{3}$ shown in figure 2 indicates that the factor $F_{3}$ is negatively correlated to packaging duration. Concerning grain size, it is positively correlated to the same factor. In short, temperature, depth level, grain size and packading duration are involved factors in the transfer of pollutants into the attiéké.

\subsection{Multiple Linear Regression}

Figure 3 shows the linear regression line between the experimental and theoretical values of BHT concentrations in the attiéké of the test and validation sets. The point cloud follows practically a straight line of equation $\mathrm{y}=0.92 \mathrm{x}+0.19$.

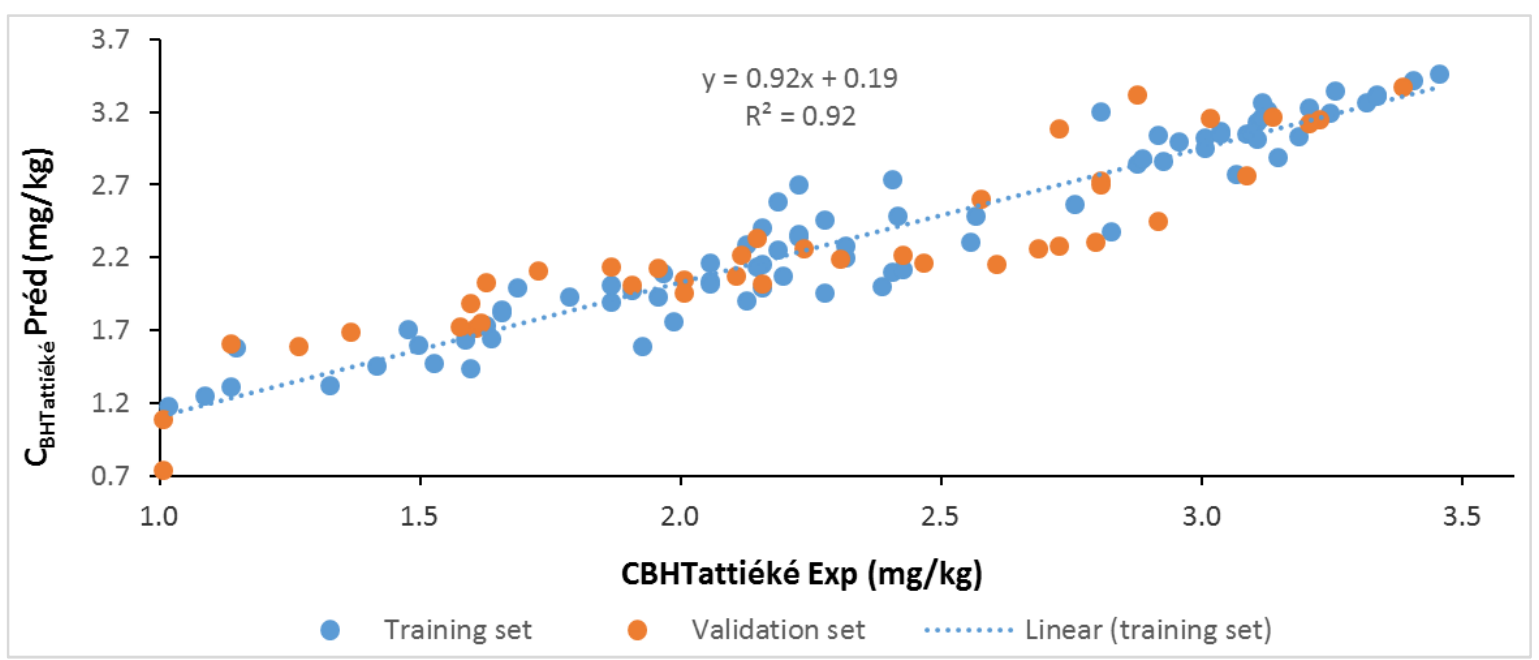

Figure 3. Multiple Linear Regression Line with Test and Validation Sets. 
The statistical indicators of the established model are:

$\mathrm{N}=80 ; \mathrm{R}^{2}=0.92 ; \mathrm{R}^{2}$ adj. $=0.915 ; Q_{C V}^{2}=0.913 ; \mathrm{RMCE}=$ $0.191 ; \mathrm{F}=170.250$

\subsection{Model Equation}

The equation of the multiple linear regression model expressing the concentration of BHT $\left(\mathrm{C}_{\mathrm{BHTatte}}\right.$ é $)$ as a function of the different parameters is given below:

$$
\begin{aligned}
\mathrm{C}_{\text {BHTattiékée }}=- & 0.40135+0.02118 \mathrm{C}_{\text {BHTsachet }}-0.09175 \mathrm{~T}_{\text {grain }}+0 . \\
& 05785 \mathrm{~T}+0.11435 \mathrm{D}-2.02658 \mathrm{P}
\end{aligned}
$$

In this equation, a positive coefficient indicates that the
BHT concentration evolves in the same direction as the descriptor. However, a negative coefficient indicates that the BHT concentration is inversely proportional to the descriptor.

\subsection{Model Validation}

Acceptance of the established model is defined as follows:

With $Q_{C V}^{2}=0.913$, the model is excellent. $\left|\mathrm{R}^{2}-Q_{C V}^{2}\right|=$ $0.007<0.3$, the model is predictive.

Fischer test gives a high value $\mathrm{F}=170.250$; which implies that this model is significant. Figure 4 shows the similarity curves between the theoretical and experimental values. Both curves look almost the same.

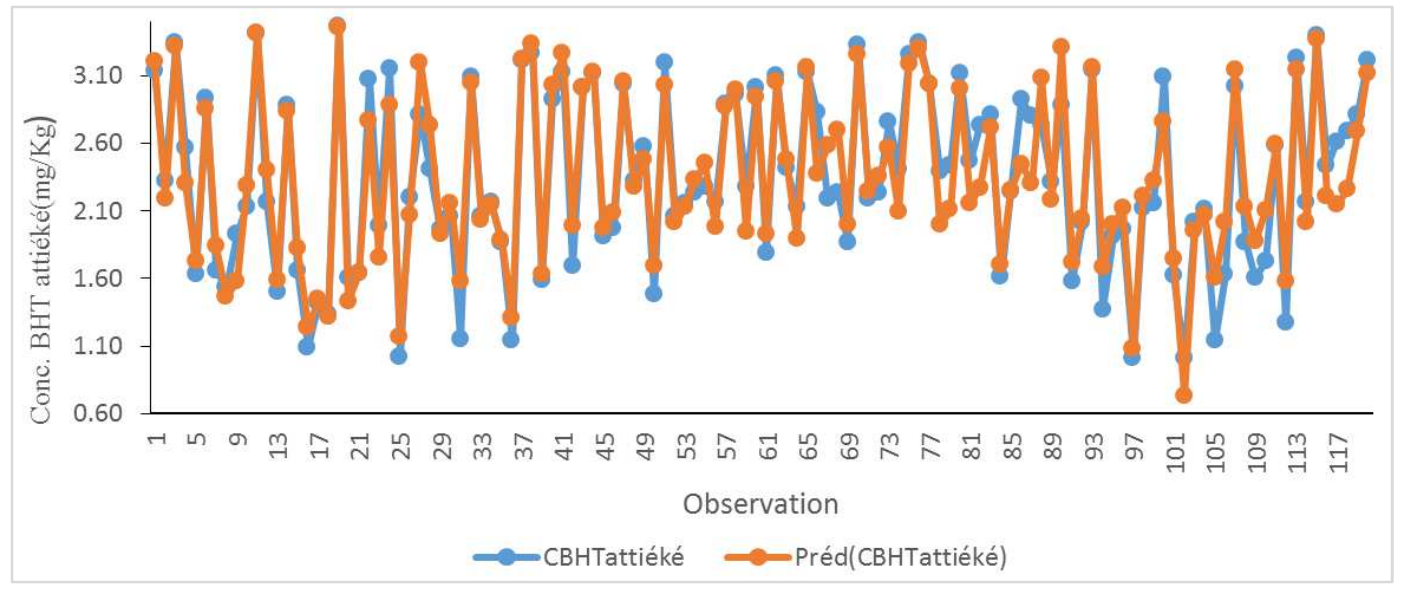

Figure 4. Similarity curve of the MLR model.

In Table 3, the theoretical and experimental concentrations of BHT in attiéké were recorded for observations of validation set. The relationships between these two quantities are almost all close to the unit.

\begin{tabular}{|c|c|c|c|c|c|c|c|}
\hline Observation & $\mathrm{C}_{\text {BHTattiéké (mg/Kg) exp }}$ & $\mathrm{C}_{\text {BHTattiéké (mg/Kg) théo }}$ & Cthéo/Cexp & Observation & $\mathrm{C}_{\text {BHTattiéké (mg/Kg) exp }}$ & $\mathrm{C}_{\text {BHTattiéké (mg/Kg) théo }}$ & Cthéo/Cexp \\
\hline 81 & 2,470 & 2,157 & 0,870 & 101 & 1,620 & 1,745 & 1,080 \\
\hline 82 & 2,730 & 2,271 & 0,830 & 102 & 1,010 & 0,731 & 0,720 \\
\hline 83 & 2,810 & 2,717 & 0,970 & 103 & 2,010 & 1,951 & 0,970 \\
\hline 84 & 1,610 & 1,704 & 1,060 & 104 & 2,110 & 2,065 & 0,980 \\
\hline 85 & 2,240 & 2,253 & 1,010 & 105 & 1,140 & 1,601 & 1,400 \\
\hline 86 & 2,920 & 2,442 & 0,840 & 106 & 1,630 & 2,017 & 1,240 \\
\hline 87 & 2,800 & 2,299 & 0,820 & 107 & 3,020 & 3,144 & 1,040 \\
\hline 89 & 2,310 & 2,181 & 0,940 & 109 & 1,600 & 1,873 & 1,170 \\
\hline 90 & 2,880 & 3,309 & 1,150 & 110 & 1,730 & 2,102 & 1,210 \\
\hline 91 & 1,580 & 1,717 & 1,090 & 111 & 2,580 & 2,593 & 1,010 \\
\hline 92 & 2,010 & 2,037 & 1,010 & 112 & 1,270 & 1,580 & 1,240 \\
\hline 93 & 3,140 & 3,158 & 1,010 & 113 & 3,230 & 3,139 & 0,970 \\
\hline 94 & 1,370 & 1,680 & 1,230 & 114 & 2,160 & 2,010 & 0,930 \\
\hline 95 & 1,910 & 2,001 & 1,050 & 115 & 3,390 & 3,367 & 0,990 \\
\hline 97 & 1,010 & 1,081 & 1,070 & 117 & 2,610 & 2,142 & 0,820 \\
\hline 98 & 2,120 & 2,209 & 1,040 & 118 & 2,690 & 2,256 & 0,840 \\
\hline 99 & 2,150 & 2,323 & 1,080 & 119 & 2,810 & 2,688 & 0,960 \\
\hline 100 & 3,090 & 2,758 & 0,890 & 120 & 3,210 & 3,115 & 0,970 \\
\hline
\end{tabular}

Table 3. Relationship between theoretical and experimental concentrations of BHT in attiéké.

\subsection{Analysis of the Contribution of Descriptors}

Figure 5 shows the descriptors that were considered in the model equation. From this figure, a classification of the most influential descriptors with their respective standardized coefficients was identified. It is the temperature $\mathrm{T}(0.846)$ followed by the depth level (from the surface to inside attiéké 
ball) $\mathrm{P}(-0.822)$. In addition, the concentration of BHT is proportional to the temperature, the packaging duration and the initial concentration of BHT in the plastic bag. However, it is inversely proportional to the grain size of the attiéké and the depth of the ball.

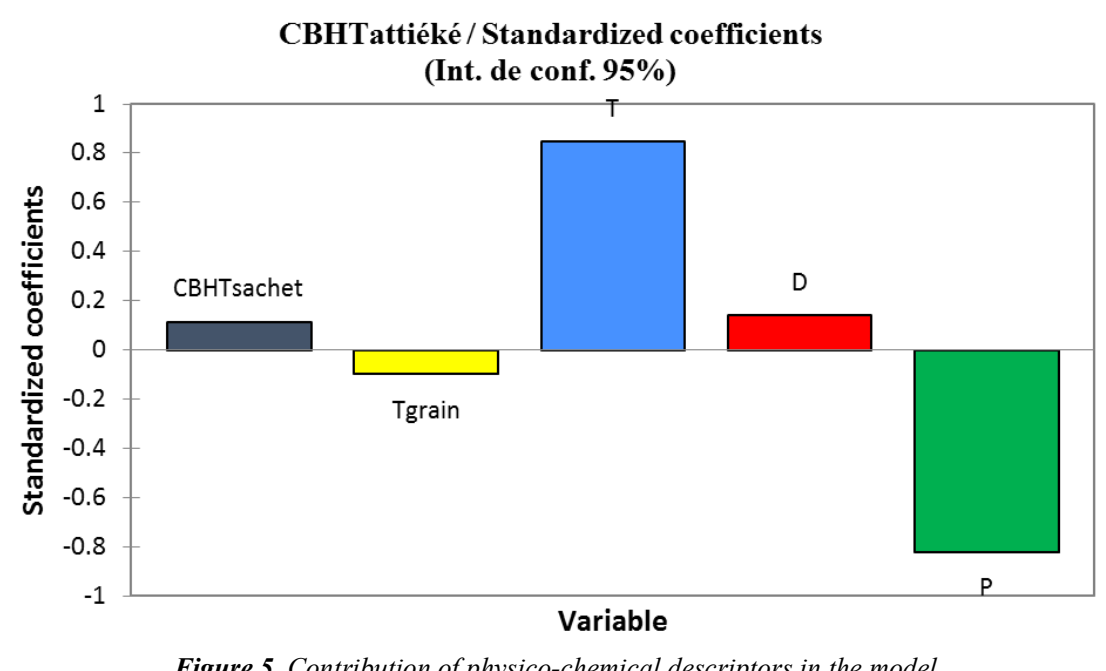

\section{Discussion}

Five (5) descriptors were taken into account in the established model. This number is in accordance with the empirical rule which stipulates that the number of descriptors should be less than or equal to about one-fifth of the number of observations in the learning set $[15,16]$. The concentration of BHT in the attiéké evolves in the same direction as the temperature, duration and initial concentration of the pollutant in the plastic bag. However, it is inversely proportional to the grain size of the attiéké and its level of depth (from surface to inside attiéké ball). In addition, temperature is the most important descriptor.

Thus, the increase in temperature considerably favours the migration of pollutants. Musoke et al. and Traistaru et al. reached the same conclusion [10,9]. Gao et al. detected the migration of BHT from plastic packaging into an aqueous simulant at a temperature of $40^{\circ} \mathrm{C}$ for a contact time of 10 days [23]. The second most important descriptor is the depth level (from the surface to the inside of the attiéké ball). The contact between the packaging and the food is made on the surface, which explains why the contents are higher on the surface than at depth. When the grain size is large, contaminants are more difficult to spread at depth. This observation is in agreement with Sakr et al. [24]. According to these authors, grain size affects the adsorption capacity of compounds. The finer the grain size, the greater the specific surface area and the greater the adsorption. According to Sauvegrain, the level of contamination of the food depends on the chemical nature of the substances, the initial amount contained in the materials, the contact surface, the nature of the contact between the materials and the food, the contact duration and the temperature [25]. The ratios of the theoretical and experimental concentrations of the validation set show that this ratio is approximately equal to one (1). This indicates that the model is acceptable. This statement is confirmed by the similarity curve between the experimental concentrations of BHT in attiéké and the theoretical concentrations. The value of the Fischer test being high $\mathrm{F}=170.2497$, it implies that the model determined is significant. Temperature, BHT concentration in plastic bag, grain size, depth level and duration provide a significant amount of information to the model [26].

The cross-validation coefficient $Q_{C V}^{2}$ is 0.9134 ; this coefficient being greater than 0.9 then the proposed model is excellent [22].

$\mathrm{R}^{2}-\mathrm{R}^{2}$ adj. $=0.005$, This difference being less than 0.3 , it can be said that descriptors choice is acceptable. The difference between $\mathrm{Q}^{2}$ and $\mathrm{R}^{2}$ is 0.0066 and therefore less than 0.3 . The model is then predictive. It can be used to predict the concentration of BHT in attiéké [21]. It should be noted that the model was based on 120 observations; this is a significant number enough to validate the model. This model can be applied for attiéké conditioning temperatures ranging from 40 to $70^{\circ} \mathrm{C}$ and for depth levels varying from the surface to $1.5 \mathrm{~cm}$ inside the attiéké ball. For conditioning temperatures between 60 and $70^{\circ} \mathrm{C}$, BHT concentrations in the attiéké are sometimes higher than the specific migration limit set by the European Union Regulation EC n ${ }^{\circ} 10 / 2011$ (3 mg/L) in the surface layer (up to $0.5 \mathrm{~cm}$ deep) [5].

\section{Conclusion}

The migration of the antioxidant BHT was modelled using the multiple linear regression method. This method was validated by various statistical indices. The determination coefficient was $\mathrm{R}^{2}=0.92$, the standard deviation was $\mathrm{RMSE}=0.1909<0.3$. The Fischer test was $\mathrm{F}=170.2497$. $Q_{C V}^{2}=0.9134>0.9$, the proposed model is excellent.

$\mathrm{R}^{2}-\mathrm{R}^{2}$ adj. $=0.0054<0.3$, then the choice of descriptors is acceptable. $Q_{C V}^{2}-\mathrm{R}^{2}=0.0066<0.3$, so the model is predictive. It can be used to predict the concentration of BHT in attiéké. All its indicators confirm that the model determined is 
excellent. This study shows that the migration of additives can be limited by the control of the conditioning temperature, which is the most important descriptor. In addition, this migration is low in depth (inside the attiéké ball) which represents the second most important descriptor here. To comply with the specific migration limit recommended by the European Union regulation, producers should condition attiéké at ambient temperature and consumers should remove the top layer (up to $0.5 \mathrm{~cm}$ ). This would limit the health risk associated with the consumption of this staple food in Côte d'Ivoire.

\section{References}

[1] Bolgar Michael, Hubball, Groeger Joe and Meronek Susan (2013). Handbook for the chemical analysis of plastic and polymer additives. CRC Press $2^{\text {ème }}$ édition Coming soon. 36p.

[2] Yang Chun z., Yaniger Stuart I., Jordan V. Craig, Klein Daniel j. and Bittner George D. (2011). Most Plastic Products Release Estrogenic Chemicals: A Potential Health Problem that Can Be Solved. Environmental health perspective, Vol. 119 (7): 989-996.

[3] Varuna P. Panicker, Sisilamma George and Dhanush Ktishna B. (2014). Toxicity study of Butylated Hyroxyl Toluene (BHT) in rats. World Journal of Pharmacy and Pharmaceutical Sciences, Vol. 3 (8): 758-763.

[4] Krabi Ekoua Regina, Assamoi Allah Antoine, Ehon Ayawovi Fafadzi, Niamké Lamine Sébastien and Thonart Philippe (2015). Production d'attiéké (couscous à base de manioc fermenté) dans la ville d'Abidjan. European scientific journal, Vol. 11 (5): 1857-7431.

[5] CE (2011). Règlement (UE) $n^{\circ} 10 / 2011$ de la commission de l'union européenne du 14 janvier 2011 concernant les matériaux et objets en matière plastique destinés à entrer en contact avec des denrées alimentaires. Journal officiel de l'union européenne, L12, 89p.

[6] Kpidi Habib Yapo, Yapo Ossey Bernard, Kone Mamadou Guy-Richard, Gadji Gabaze Andre, Gnagne Agness Essoh Jean-Yves Eudes, N'dri Jean Stephane and Ziao Nabosse (2018). Monotiring and Modeling of Chorophyll-a Dynamics in a Eutrophic Lake: N'koa Lake (Jacqueville, Ivory Coast), American Journal Of Environmental Protection, Vol. 6 (1): 19.

[7] Ouattara Ouanlo, Kone Mamadou Guy-Richard, Affi Thomas Sopi, Bamba Kafoumba, Traore Yafigui and Ziao Nahossé (2018). Contribution To The Molecular Lipophilicity Scale By Qspr Models Of Lipophilicity Prediction, Journal of Engineering Research and Application, Vol. 8 (7): 55-61.

[8] Maalouf Jean Paul (2016). Introduction à la modélisation statistique. 44p.

[9] Traistaru Elena, Rivis Adrian, Moldovan Ciprian Raul, Menelaou Antigoni and Cecilia Georgescu (2013). Modelling migration from plastic packaging materials used in food industry. Journal of Agromentary Processes and Technologies. Vol. 19 (2): 180-184.

[10] Musoke L., Banadda N., Sempala C. and Kigozi J. (2015). The Migration of Chemical Contaminants from Polyethylene Bags into Food During Cooking. The Open Food Science
Journal, Vol. 9: 14-18.

[11] Microsoft (®) Excel ${ }^{\circledR} \quad(2013)$ (15.0.4420.1017) $\quad$ MSO (15.0.4420.1017) 64 Bits (2013) Partie de Microsoft Office Professionnel Plus.

[12] XLSTAT Version 2014.5.03 Copyright Addinsoft 1995-2014 (2014) XLSTAT and Addinsoft are Registered Trademarks of Addinsoft. https://www.xlstat.com.

[13] Kombo Mananga Olivier Simon, Gnagne Agnes Essoh JeanYves Eudes, Gadji Alahou André Gabazé, Ballet Guy Tiama and Yapo Ossey Bernard (2019a). Migration of Plastic Bag Additives In Attiéké (A Fermented Cassava-based Couscous in Côte d'Ivoire). Australian Journal of Basic and Applied Sciences, 13 (11): 10-18.

[14] Kombo Mananga Olivier Simon, Gnagne Agnes Essoh JeanYves Eudes, Ahoule Dompe Ghislain Maxime and Yapo Ossey Bernard, (2019b). Method Of Determination Of Antioxidant, Phthalates and Ultraviolet Absorbers in Attiéké « Couscous From Fermented Cassava "Before its Storage. Journal of Chemical, Biological and Physical Sciences, Vol. 9 (2): $269-280$.

[15] Topliss J. G. and Edwards R. P. (1979). Chance factors in studies of quantitative structure-activity relationships, Journal of Medicinal Chemistry, Vol. 22 (10): 1238-1244.

[16] Ghamadi Mounir, Chtita Samir, Bouachrine Mohammed and Lakhlift Tahar (2016). Méthodologie générale d'une étude RQSA/RQSP. Revue Interdisciplinaire. Vol. 1, 6p.

[17] Gallina N., Anneville O. and Beniston M. (2010). Impacts of extreme air temperatures on cyanobacteria in five deep periAlpine lakes. J. Limnol., Vol. 70: 186-196.

[18] Snedecor G. W. and cochran W. G. (1967). Statistical Method. Oxford and IBH, New Delhi, India, 381p.

[19] Traoré Yafigui, Kone Mamadou Guy-Richard, Ouattara Ouanlo and Ziao Nahossé (2018). QSAR Approach to Estimating the Analgesic Activity of a Serie of Tri-Substituted Pyrimidine Derivatives, Journal of Computational Chemistry \& Molecular Modelling, Vol. 2 (4): 1-14.

[20] Soro Doh, Ekou Lynda, Kone Mamadou Guy-Richard, Ekou Tchirioua, Affi Sopi Thomas, Ouattara Lamoussa and Ziao Nahossé (2018). Prediction of the Inhibitory Concentration of Hydroxamic Acids by DFT-QSAR Models on Histone Deacetylase 1, International Research Journal of Pure \& Applied Chemistry, Vol. 16 (2): 1-13.

[21] Veerasamy Bavichandran, Rajak Harish, Jain Abbishek, Sivadasan Shalini, Varghese P. Christapher and Agrawal Kishore Ram (2011). Validation of QSAR Models-Strategies and Importance. International Journal of Drug Design and discovery, Vol. 2 (3): 511-519.

[22] Eriksson Lennart, Jaworska Joanna, Worth Andrew P., Cronin Mark T. D., Mcdowell Robert M. and Gramatica Paola (2003). Methods for Reliability and Uncertainty Assessment and for Applicability Evaluations of Classification- and RegressionBased QSARs. Environmental Health Perspectives, Vol. 111 (10): 1361-1375.

[23] Gao Y., Gu Y. and Xei Y. (2011). Determination of polymer coumpouds-antioxidants and ultraviolet (UV) absorbers by High-Performance Liquid Chromatography coupled with UV photodiode array detection in food simulants. J. Agric. Food. Chem, Vol. 59: 12982-12989. 
[24] Sakr F., Sennaoui A., Elouardi M., Tamini M. and Assabbane A. (2015). Etude de l'adsorption du bleu de méthylène sur un biomatériau à base de Cactus. J. Mater. Environ. Sci, Vol. 6 (2): 397-406.

[25] Sauvegrain Patrick (2014). Phenomène de migration des matières plastiques au contact des aliments et réglementation. Laboratoire National de métrologie et d'essais. 3p.
[26] Kouakou Konan Jean-Marie, Yao Brou Lazare, Kpan Kpan Kouakou Gains, Dembele Ardjouma et Traore Karim Sory (2015). Méthode de dosage de la fumonisine B1 dans les matrices de céréales: cas du sorgho (Sorghum bicolor) et du mil (Pennisetum spp). Afrique Science, Vol. 11 (5): 378-390. 